\title{
The crystal structure of brunogeierite, $\mathrm{Fe}_{2} \mathrm{GeO}_{4}$ spinel
}

\author{
M. D. $\mathrm{WeLCH}^{1,2, *}$, M. A. CoOper ${ }^{2}$ And F. C. Hawthorne ${ }^{2}$ \\ ${ }^{1}$ Department of Mineralogy, The Natural History Museum, Cromwell Road, London SW7 5BD, UK \\ ${ }^{2}$ Department of Geological Sciences, University of Manitoba, Winnipeg, Manitoba, Canada R3T 2N2
}

\section{ABSTRACT}

Brunogeierite, $\mathrm{Fe}_{2} \mathrm{GeO}_{4}, a=8.4127(7) \AA, V=595.4(1) \AA^{3}$, is a rare germanate spinel from Tsumeb, Namibia. Its structure has been refined to an $R$ index of $2.2 \%$. The oxygen parameter, $u$, is $0.2466(1)$, indicating nearly ideal cubic close-packing of oxygen atoms. There is exact agreement between the observed $a$ unit-cell dimension and that calculated from the observed $\mathrm{Ge}-\mathrm{O}$ and $\mathrm{Fe}-\mathrm{O}$ bond lengths. The cations $\mathrm{Ge}$ and $\mathrm{Fe}$ are fully ordered at tetrahedral $(A)$ and octahedral $(B)$ sites, respectively, in keeping with synthetic germanate spinels, all of which are fully-ordered normal spinels.

KEYworDs: brunogeierite, spinel, crystal structure.

\section{Introduction}

GermanAtes are frequently used as structural analogues of high-pressure silicates because they allow phase transformations and structural behaviour to be studied at pressures that are more routinely accessible experimentally than those for the corresponding silicate systems. The spinel $\mathrm{Mg}_{2} \mathrm{GeO}_{4}$ is the low-pressure analogue of ringwoodite, $\gamma-\mathrm{Mg}_{2} \mathrm{SiO}_{4}$, and has been used to model high-pressure behaviour of the latter. There was some debate about the state of $\mathrm{Mg}-\mathrm{Ge}$ order (degree of inversion) in this spinel, until Von Dreele et al. (1977) showed that it is completely ordered on the normal scheme ( $A=\mathrm{Ge}, B=\mathrm{Mg})$. The present study was undertaken to determine the state of order in the natural germanate analogue of $\gamma-\mathrm{Fe}_{2} \mathrm{SiO}_{4}$ : brunogeierite, $\mathrm{Fe}_{2} \mathrm{GeO}_{4}$.

Almost all recent structural studies of germanate spinels have been done on powder samples, reflecting both the difficulty of synthesizing crystals of sufficient quality for single-crystal work and the rarity of good natural samples. We acquired a high-quality specimen of brunogeierite (Tsumeb, Namibia) from Mr William Pinch, and we report the structure refinement of this crystal here.

* E-mail: markwelch@nhm.ac.uk

\section{Experimental}

\section{$X$-ray diffraction}

Brunogeierite from Tsumeb occurs as $40-50 \mu \mathrm{m}$ thick crusts on tennantite cores (Otteman and Nuber, 1972), the aggregates forming octahedra. A partial octahedron was removed from the sample and a $37 \mu \mathrm{m}$ thick $\{111\}$ plate prepared by grinding away the attached tennantite. The bounding faces of the plate form an equilateral triangle $170 \mu \mathrm{m}$ on each side. Zero-level precession photographs down two $a$ axes revealed a very minor secondary component $(<5 \%)$. This component had a diffraction pattern similar to that of the main portion of the brunogeierite and represents a second single crystal. The diffraction maxima of this secondary component are displaced sufficiently from those of the main crystal so as not to interfere; careful examination of all background regions adjacent to the diffraction maxima of the main crystal confirmed this.

The crystal plate was attached to a glass fibre and mounted on a Siemens P4 automated four-

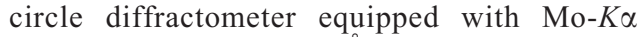
radiation $(\lambda=0.71073 \AA)$. All twelve Laue equivalents of $\{440\}$ were centred and the unitcell parameter was refined by least-squares to give $a=8.4127(7) \AA, V=595.4(1) \AA^{3}$. A whole sphere of data was collected in the range $4-60^{\circ} 2 \theta$ $(\overline{1} \overline{1} \overline{1} \overline{1} \overline{1} \rightarrow 111111)$. Reflections were scanned in $\omega-2 \theta$ mode at a variable speed of $2-19^{\circ} 2 \theta / \mathrm{min}$; 
TABLE 1. Miscellaneous information relating to structure determination and refinement.

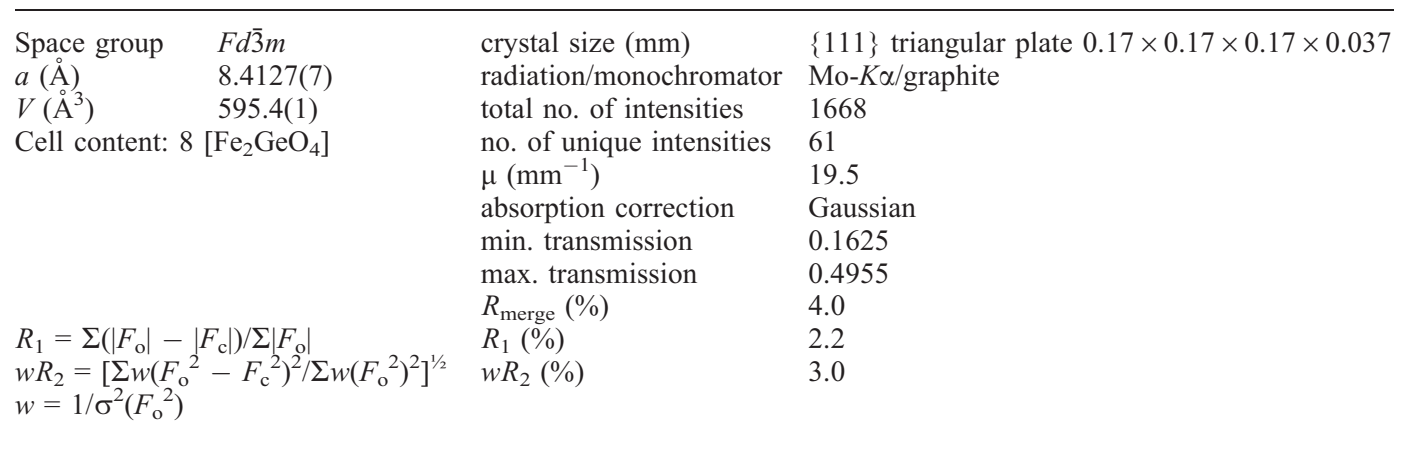

one check reflection was measured every 50 reflections. A total of 1668 intensities was collected, of which 61 were unique. A Gaussian absorption correction was applied and the crystal was modelled as a triangular plate with minimum and maximum transmission values of 0.1625 and 0.4955 , respectively. Background, Lorentz polarization and absorption corrections were applied to the raw intensities which were then reduced to structure factors. Sixteen reflections violating the $d$ glide were observed $\left(F^{2} / \sigma F^{2}>20\right)$, but psi scans of these reflections showed that their presence is due to double diffraction. Consequently, $F d \overline{3} m$ was confirmed as the correct space group. The structure of brunogeierite was refined in space group $F d \overline{3} m$ using the Siemens SHELXTL PLUS software package, $F^{2}$ values for all data, ionic scattering factors and a minor extinction correction. The refined site occupancies indicate that $\mathrm{Ge}$ and $\mathrm{Fe}$ are fully ordered at the $A$ and $B$ sites, respectively, i.e. $\mathrm{Fe}_{2} \mathrm{GeO}_{4}$ is a normal spinel. Therefore, the final stages of refinement were performed with site occupancies fixed at $A=\mathrm{Ge}$ and $B=\mathrm{Fe}$.

The structure refined smoothly to an $R$ index of $2.2 \%$ for an anisotropic-displacement model. Details relating to the structure solution and refinement are summarized in Table 1. Atom coordinates and displacement parameters are given in Table 2, and structure factors in Table 3.

\section{Results and discussion}

The $\mathrm{Ge}-\mathrm{O}$ and $\mathrm{Fe}-\mathrm{O}$ bond-lengths for brunogeierite are 1.771(2) and 2.132(1) ̊, respectively. The value for the oxygen parameter $u$ in brunogeierite is $0.2466(1)$. The $u$ value for ideal cubic close-packing of oxygen is 0.25 ; hence, brunogeierite has nearly perfect cubic closepacking of oxygen anions. The $\mathrm{Ge}-\mathrm{O}$ bond length is equal to the sum of the ionic radii $(0.39+1.38=1.77 \AA$; Shannon, 1976). The $\mathrm{Fe}-\mathrm{O}$ bond is slightly shorter than the sum of the ionic radii $(0.78+1.38=2.16 \AA)$. The $A$ site refined to full occupancy by Ge; hence, there is no evidence for a magnetite component in solid solution in brunogeierite - it has $\mathrm{Ge}$ and $\mathrm{Fe}$ completely ordered at the $A$ and $B$ sites, respectively. This cation distribution is in keeping with synthetic germanate spinels $\mathrm{Mg}_{2} \mathrm{GeO}_{4}, \mathrm{Co}_{2} \mathrm{GeO}_{4}$ and $\mathrm{Ni}_{2} \mathrm{GeO}_{4}$ (Von Dreele et al., 1977; Hill et al., 1979). The synthetic highpressure phase $\gamma-\mathrm{Fe}_{2} \mathrm{SiO}_{4}$ is also fully ordered on the normal scheme and has $u=0.2409$ (Finger et

TABLE 2. Atom coordinates and displacement parameters $\left(\times 10^{4} \AA^{2}\right)$ for brunogeierite.

\begin{tabular}{lcccccccccc}
\hline & $x$ & $y$ & $z$ & $U_{\mathrm{eq}}$ & $U_{11}$ & $U_{22}$ & $U_{33}$ & $U_{23}$ & $U_{13}$ & $U_{12}$ \\
\hline $\mathrm{Ge}$ & $1 / 8$ & $1 / 8$ & $1 / 8$ & $46(3)$ & $46(3)$ & $46(3)$ & $46(3)$ & - & - & - \\
$\mathrm{Fe}$ & $1 / 2$ & $1 / 2$ & $1 / 2$ & $61(3)$ & $61(3)$ & $61(3)$ & $61(3)$ & $4(2)$ & $4(2)$ & $4(2)$ \\
$\mathrm{O}$ & $0.2466(1)$ & $0.2466(1)$ & $0.2466(1)$ & $62(5)$ & $62(5)$ & $62(5)$ & $62(5)$ & $-15(7)$ & $-15(7)$ & $-15(7)$ \\
\hline
\end{tabular}




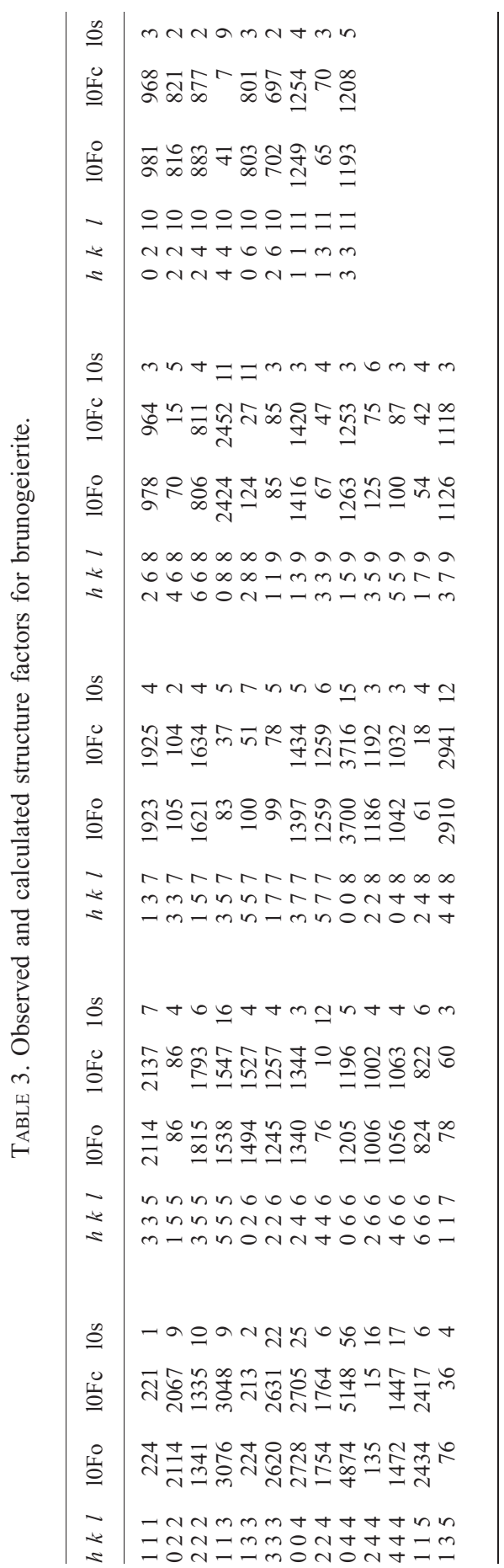


al., 1979), reflecting the smaller size of the $A$ cation $(\mathrm{Si})$ and shortening of shared octahedral edges. There is no shortening of shared octahedral edges in brunogeierite; in fact, the unshared octahedral edges $(2.98 \AA)$ are slightly shorter than the shared edges $(3.05 \AA)$. We note that there is perfect agreement between the observed unitcell parameter and that calculated from the $\mathrm{Ge}-\mathrm{O}$ and $\mathrm{Fe}-\mathrm{O}$ bond lengths using the formulae of Hill et al. (1979), indicating that the unit-cell parameter and atom positions are fully consistent in the brunogeierite structure.

\section{Acknowledgements}

We thank Bill Pinch for donating the brunogeierite specimen from which the crystal for this study was taken. Financial support was provided by Natural Sciences and Engineering Major Facilities Access, Major Equipment and Research grants to $\mathrm{FCH}$.

\section{References}

Finger. L.W., Hazen, R.M. and Yagi, T. (1979) Crystal structures and electron densities of nickel and iron silicate spinels at elevated temperature or pressure. Amer. Mineral., 64, 1002-9.

Hill, R.J., Craig, J.R. and Gibbs, G.V. (1979) Systematics of the spinel structure type. Phys. Chem. Miner., 4, 317-39.

Otteman, J. and Nuber, B. (1972) Brunogeierit, ein germanium-ferritspinel von Tsumeb. Neues Jahrb. Mineral. Mon., 263-7.

Shannon, R.D. (1976) Revised effective ionic radii and systematic studies of interatomic distances in halides and chalcogenides. Acta Crystallogr., A32, 751-67.

Von Dreele, R.B., Navrotsky, A. and Bowman, A.L. (1977) Refinement of the crystal structure of $\mathrm{Mg}_{2} \mathrm{GeO}_{4}$ spinel. Acta Crystallogr., B33, 2287-8.

[Manuscript received 27 July 2000:

revised 13 March 2001] 